University of Nebraska - Lincoln

DigitalCommons@University of Nebraska - Lincoln

2009

\title{
Body Size and Predatory Performance in Wolves: Is Bigger Better?
}

Daniel R. MacNulty

University of Minnesota,St. Paul

Douglas W. Smith

Yellowstone Centre for Resources

L. David Mech

USGS Northern Prairie Wildlife Research Centre, david_mech@usgs.gov

Lynn E. Eberly

University of Minnesota, Minneapolis, lynn@biostat.umn.edu

Follow this and additional works at: https://digitalcommons.unl.edu/usgsnpwrc

Part of the Other International and Area Studies Commons

MacNulty, Daniel R.; Smith, Douglas W.; Mech, L. David; and Eberly, Lynn E., "Body Size and Predatory Performance in Wolves: Is Bigger Better?" (2009). USGS Northern Prairie Wildlife Research Center. 70. https://digitalcommons.unl.edu/usgsnpwrc/70

This Article is brought to you for free and open access by the US Geological Survey at DigitalCommons@University of Nebraska - Lincoln. It has been accepted for inclusion in USGS Northern Prairie Wildlife Research Center by an authorized administrator of DigitalCommons@University of Nebraska - Lincoln. 


\title{
Body size and predatory performance in wolves: is bigger better?
}

\author{
Daniel R. MacNulty ${ }^{1 *}$, Douglas W. Smith ${ }^{2}$, L. David Mech ${ }^{3}$ and Lynn E. Eberly ${ }^{4}$ \\ ${ }^{1}$ Department of Ecology, Evolution and Behaviour, University of Minnesota, 1987 Upper Buford Circle, St. Paul, MN 55108, \\ USA; ${ }^{2}$ Yellowstone Centre for Resources, PO Box 168, Yellowstone National Park, WY 82190, USA; ${ }^{3}$ US Geological \\ Survey, Northern Prairie Wildlife Research Centre, 8711 37th Street SE, Jamestown, ND 58401, USA; and ${ }^{4}$ Division of \\ Biostatistics, School of Public Health, University of Minnesota, 2221 University Avenue, Minneapolis, MN 55414, USA
}

\begin{abstract}
Summary
1. Large body size hinders locomotor performance in ways that may lead to trade-offs in predator foraging ability that limit the net predatory benefit of larger size. For example, size-related improvements in handling prey may come at the expense of pursuing prey and thus negate any enhancement in overall predatory performance due to increasing size.

2. This hypothesis was tested with longitudinal data from repeated observations of 94 individually known wolves (Canis lupus) hunting elk (Cervus elaphus) in Yellowstone National Park, USA. Wolf size was estimated from an individually based sex-specific growth model derived from body mass measurements of 304 wolves.

3. Larger size granted individual wolves a net predatory advantage despite substantial variation in its effect on the performance of different predatory tasks; larger size improved performance of a strength-related task (grappling and subduing elk) but failed to improve performance of a locomotor-related task (selecting an elk from a group) for wolves $>39 \mathrm{~kg}$.

4. Sexual dimorphism in wolf size also explained why males outperformed females in each of the three tasks considered (attacking, selecting, and killing).

5. These findings support the generalization that bigger predators are overall better hunters, but they also indicate that increasing size ultimately limits elements of predatory behaviour that require superior locomotor performance. We argue that this could potentially narrow the dietary niche of larger carnivores as well as limit the evolution of larger size if prey are substantially more difficult to pursue than to handle.
\end{abstract}

Key-words: carnivores, elk, predator ontogeny, size-dependent foraging ability, wolves

\section{Introduction}

Body size imposes fundamental and sometimes opposing constraints on the functional performance of vertebrates. For example, smaller animals enjoy greater burst acceleration and manoeuvrability than do larger animals (Biewener 2003; Dial, Greene \& Irschick 2008) but larger animals can handle larger food items via increased gape size and bite force (Nilsson \& Bronmark 2000; Herrel \& O'Reilly 2006). Predators that pursue prey require superior locomotor performance to get within reach of prey as well as excellent handling ability to grab and overpower prey. Whether or not such predators can simultaneously maximize pursuit and

*Correspondence author. E-mail: macn0007@umn.edu handling performance as they increase in size, either ontogenetically or phylogenetically, is not clear. Conceivably, the contrasting effects of size on pursuing and handling lead to a predatory trade-off in size, such that a size-related improvement in handling leads to a concomitant reduction in pursuing and vice versa.

The hypothesis that increasing predator size hinders foraging ability differs from the prevailing view that larger predators generally outperform smaller predators (Herrel \& Gibb 2006; Vincent et al. 2007). However, the strength of this generalization is questionable because previous studies of size-related variation in predator performance have mainly examined aspects of handling behaviour while ignoring other phases of the predatory sequence such as the pursuit (e.g., Binder \& Van Valkenburgh 2000; Van Wassenbergh, Aerts \& Herrel 2005; Brecko et al. 2008). This approach may be 
misleading because it emphasizes a phase of predator performance that is biomechanically favoured to improve with increasing predator size, and reveals nothing about the net effect of predator size across the different phases of predation. The latter is important because handling ability could increase with size even as overall predatory ability drops due to performance declines in other phases. This is possible because the net outcome of a predator-prey interaction is the product of the outcome at each phase (Lima \& Dill 1990). Thus, as predators increase in size, trade-offs in foraging ability between pursuing and handling could limit the net predatory benefit of larger size.

The notion that bigger predators are overall better hunters is well established among studies of carnivorous land mammals, and has been cited to explain why bigger carnivores take bigger prey (Gittleman 1985) and why carnivores in general have evolved towards larger size (Van Valkenburgh, Wang \& Damuth 2004). But apart from broad-scale comparisons demonstrating that bigger species and the bigger sex (males) kill larger prey (Gittleman 1985; Carbone et al. 1999; Sinclair, Mduma \& Brashares 2003; Radloff \& Du Toit 2004; Carbone, Teacher \& Rowcliffe 2007; Owen-Smith \& Mills 2008), the extent to which increasing size improves the overall predatory performance of individual hunters remains untested. Evidence that male lions (Panthera leo) are worse than female lions at chasing fleet-footed prey but better at grappling larger prey that stand and fight (Funston et al. 1998; Funston, Mills \& Biggs 2001) suggests that increased size may improve handling at the expense of pursuing. Such a trade-off might explain, in part, why the largest carnivores lack cursorial morphology, in which elbow joints are limited to fore-aft movements (Andersson $\&$ Werdelin 2003), and prefer the largest prey (Owen-Smith \& Mills 2008).

Here we use direct observations of individually known wolves (Canis lupus) hunting elk (Cervus elaphus) in Yellowstone National Park (YNP) to test the hypothesis that predatory trade-offs in body size limit the net predatory benefit of larger size. To do so, we measured how within-wolf variation in body mass (kilogram) affected the ability of individuals to perform each of three predatory tasks (attacking, selecting, and killing) corresponding to the transitions between four phases of behaviour (approach, attack-group, attack-individual, capture) that comprise the typical predatory sequence of cursorial carnivores hunting groups of ungulate prey (MacNulty, Mech \& Smith 2007). Selecting requires choosing one ungulate from a group by chasing or harassing the group. This involves a significant burst of speed (Kruuk 1972; MacNulty et al. 2007), so we predicted performance of this task to reach a size threshold beyond which performance declined. Conversely, we expected killing ability, which involves grabbing and overpowering prey (i.e., handling), to increase linearly with size, and predicted little effect of size on attacking since neither great strength nor exceptional speed are crucial to initiating an attack. We tested these predictions with longitudinal data from repeated observations of 94 focal wolves whose sizes were estimated from an individually based sex-specific growth model.

\section{Methods}

\section{STUDY AREA}

YNP extends across 891000 ha of a primarily forested plateau in north-western Wyoming, USA, that ranges from 1500 to $3300 \mathrm{~m}$. Large montane grasslands provide excellent views of wildlife. Observations of wolves hunting were made primarily in a 100 000-ha grassland complex in the north-eastern quarter of YNP referred to as the northern range. This area is characterized by a series of open valleys, ridges, and minor plateaus. Low elevations (1500 to $2000 \mathrm{~m}$ ) there create the warmest and driest conditions in YNP during winter, providing critical winter range for ungulates, including mainly elk. A maintained road runs the length of the northern range and provides year-round vehicle access.

\section{STUDY POPULATION}

A combined total of 41 radio-marked wolves were re-introduced to YNP in 1995 and 1996 (Bangs \& Fritts 1996). Thirty-one wolves (16 adults, 15 pups) were from Canada, and 10 (all pups) were from an established population in north-western Montana, USA. Wolves included in our analyses were either members or descendents of this re-introduced population. The growth analysis included all reintroduced wolves and 263 of their descendents $(N=304)$, and the predation analysis included 19 re-introduced wolves and 75 descendents $(N=94)$. Wolves were included in the predation analysis if they were seen hunting elk and individually recognizable by combination of radio frequency, colour pattern, body conformation, and/or size. We refer to these individuals as focal wolves.

\section{MORPHOLOGICAL MEASUREMENTS}

The age, sex, and body size of 86 focal and 218 nonfocal wolves was recorded when they were handled and radio-marked during management pre- and post-release (1995-97) and annually thereafter (1998-2007) as part of long-term monitoring that involved capturing and radio-marking $30-50 \%$ of pups each winter (Smith et al. 2004). Marking pups and identifying them later provided the only exact measure of age because they were readily identified by size and dentition (Van Ballenberghe \& Mech 1975). The age of adult wolves was estimated by evaluating tooth wear, which is subjective and depends on observer experience (Gipson et al. 2000). Estimates of age based on cementum annuli (Matson's Laboratory, Milltown, MT, USA) were limited to six wolves whose skulls were recovered after death.

Pups that escaped capture were sometimes caught later as adults, and were considered known-aged if individually known between when identified as pups and when captured as adults. Otherwise, their ages were estimates based on tooth wear. We assigned ages to noncaptured wolves, including eight focal wolves, only if first observed as pups and individually identifiable as adults. For all wolves, age was the number of days since birth, assuming a 15 April birth date (D.W. Smith, unpublished data), and calculated as an annual fraction. Known-aged wolves represented most of the sample in our analyses of growth ( $77 \%$ of 304 wolves) and hunting ( $82 \%$ of 94 wolves), and results were similar between analyses with and without individuals with estimated ages. We report results from the former because our objective was to test the effects of size on predatory ability and most of our largest wolves were adult members of the re-introduced population whose ages were estimated. 
Wolf sex was determined by examining genitalia. Sex of noncaptured wolves was determined by noting urination postures; males generally lean forward whereas females squat.

Body mass was recorded using a $0-100 \mathrm{~kg}$ Pesola spring scale (Rebmattli, Baar, Switzerland). Wolves were placed in a weighing tarp attached to the scale and hoisted aloft until clear of the ground. We did not estimate and subtract stomach-content mass from body mass, so our measurements should be considered maximum estimates. We also recorded chest girth (measured immediately behind the forelegs), shoulder height (measured from the middle of the backbone along the straightened leg to the tip of the extended foot), and body length (skull and vertebral column excluding the tail from the tip of the nose to the sacrococcygeal joint). About $25 \%$ of marked wolves were caught in multiple years to replace damaged radio-tags, and so were weighed multiple times. The other morphometrics were typically noted during the initial capture only.

\section{BEHAVIOURAL OBSERVATIONS}

The methods used to observe and record predatory behaviour were described by MacNulty et al. (2007), and here we highlight only key aspects relevant to the current analysis. Various assistants and two of the authors (D.R.M. and D.W.S.) observed wolves hunting elk during systematic annual surveys of 3-14 packs from the ground and fixed-wing aircraft in early (mid-November to mid-December) and late (March) winter and during opportunistic surveys throughout the remainder of the year. Elk were the main prey for wolves, comprising $92 \%$ of their diet (Smith et al. 2004), and $97 \%$ of wolfelk encounters $(N=469)$ were witnessed by ground observers in the Northern Range. Most encounters (84\%) involved groups of elk.

When wolves encountered elk - defined as at least one wolf orienting and moving (walking, trotting or running) towards elk - we closely watched focal wolves, but we usually could not follow them continuously because they were often viewed at long distances $(0 \cdot 1-$ $6.0 \mathrm{~km})$ in variable terrain among the hurried movements of elk (2-800 elk) and other pack members (2-27 wolves). Nevertheless, we could track the progress of a wolf-elk encounter by noting the foraging state (approach, watch, attack-group, attack-individual, capture) of the individual(s) closest to making a kill. We therefore recorded the sequential occurrence of the most escalated state and the identity of wolves participating in that state.

A wolf was scored as participating in a foraging state if it exhibited the behavioural acts characterizing that particular state (see Table 2 in MacNulty et al. 2007). Nonparticipation was when a wolf was in view but engaged in another foraging state or nonpredatory behaviour, e.g., resting. If the state escalated, i.e., transitioned to the next predatory behaviour, and a wolf continued participating, it was scored as performing the corresponding predatory task (e.g., attacking-group $\rightarrow$ attack-individual $=$ selecting). If the state did not escalate, or the wolf stopped participating, then the wolf's performance was scored as a failure (e.g., attacking-group $\rightarrow$ approach). Task performance was therefore equivalent to consecutive participation in a pair of sequential foraging states that comprised a particular predatory task. Observations were dictated into voice recorders, noting times with digital stopwatches, and/or recorded with video cameras. Focal wolves were observed for 1-8 years (1995-2003).

\section{STATISTICAL ANALYSIS}

To assess the effects of size on predatory performance, we relied on indirect estimates of size because it was not feasible to directly measure wolves immediately before or after a hunt. We therefore used measurements taken at other times to first develop a growth model from which to predict the size of wolves seen hunting. We then analysed how the predicted size of wolves influenced their ability to perform each of three different predatory tasks (attacking, selecting and killing). Statistical methods for analyzing growth and predation were similar in three respects.

First, mixed effects models were used to account for correlation between repeated observations of the same wolves. We used general linear mixed models (GLMM) to predict the body mass (an index of overall body size - see Results) of focal wolves, and generalized linear mixed models (GZLMM) with a logit link to assess how predicted mass influenced the probability that a focal wolf performed each predatory task. Both sets of models were structured and estimated similarly in the STATA 10 analysis package. Models included a wolf-specific random intercept, which allowed, for example, individual wolves to be overall larger or smaller, and a compound symmetric covariance structure, which assumed that all observations within individuals were, on average, equally correlated (Weiss 2005). Models were estimated with adaptive Gaussian quadrature, with parameters estimated from maximum likelihood, and significance of effects determined by an approximate $z$-test.

Second, an information theoretic approach was used to evaluate different models that reflected different hypotheses about how wolf age and sex determined body mass, and how body mass in turn affected predatory performance. Our scope of inference concerned the population, so we compared marginal models using Akaike's information criterion corrected for small samples ( $\mathrm{AIC}_{c}$; Burnham $\&$ Anderson 2002). $\mathrm{AIC}_{c}$ calculations included one additional parameter for the random intercept. We used delta $\mathrm{AIC}_{c}\left(\mathrm{AIC}_{c}\right)$ scores to rank nested and non-nested models based on Akaike weights, $W_{i}$, for each model. The Akaike weights can be interpreted as the weight of evidence, or probability, that model $i$ is the best approximating model, given the data and set of candidate models.

Third, nonlinear patterns in growth and predation were modelled as linear regression splines and $\mathrm{AIC}_{c}$ was used to choose the best breakpoints. Candidate breakpoints were selected by inspecting Lowess plots of the raw data. In the growth analysis, one spline variable (age_3) was made to apply only to males to test for apparent intersexual differences in body mass at advanced ages. This was accomplished by setting values of the age_3 covariate to 0 for all female records. We further tested for intersexual growth differences by including age $\times$ sex interactions in each model set. In the predation analysis, we used splines only after first screening for nonlinear trends with polynomial models.

Each time a focal wolf was seen hunting, its mass was predicted from the best-fit growth model. This was accomplished by taking the wolf's age- and sex-appropriate linear combination of regression spline coefficients and adding to this the value of its random intercept plus a measurement error generated as a random draw (independently and identically distributed) from a normal distribution with mean 0 and standard deviation equal to the growth model's estimated standard deviation of the overall error term $(4.66 \mathrm{~kg})$. We added random error to account for how field measurements of wolves, had they been taken immediately before or after a hunt, would have been imperfect. We did not use multiple imputation (i.e., random draws with replication) because the 'final' model that results from combining individual imputed models contains no log-likelihood and thus prevents model selection. We therefore used single imputation because it added realism to our body mass predictions without sacrificing our ability to analyse how body mass affected predation. Following this logic, we also generated a random intercept for the eight focal wolves that were never captured as a random draw from 
a normal distribution with mean 0 and standard deviation equal to the growth model's estimated standard deviation of the randomintercept $(2.64 \mathrm{~kg})$. We used these random intercepts each time we computed the mass of these eight wolves. Results with and without randomly drawn errors and intercepts were nearly identical, but we report only those with the random draws as we believe they best approximate the association between predatory ability and actual measurements of body mass.

We gauged the validity of mass as an index of overall body size by measuring the strength of association between mass and three other morphometrics (chest girth, body length, and shoulder height). Data for these measurements were insufficient for a mixed effects analysis, so we used simple linear regression (SLR) to analyse their associations with mass by first randomly selecting a single record for the few wolves in which multiple records did occur. Body mass was treated as the predictor variable in each analysis. We tested for a nonlinear association between shoulder height and body mass with linear regression splines using the model selection procedure described above. All morphometric variables satisfied assumptions of normality.

We separately analysed the effects of mass on the performance of each predatory task. The number of wolves and encounters included in each task analysis varied as follows: attacking ( 87 wolves, 258 encounters), selecting ( 81 wolves, 281 encounters), and killing (74 individuals, 189 encounters). To increase sample size, encounters with elk groups and solitary elk were combined in analyses of attacking and killing after verifying that results did not differ when groups and singletons were examined separately. Singletons were adult $(>1$ year) elk, whereas groups typically included calves ( $<1$ year). Analyses of killing involved mainly adult elk ( $92 \%$ of 189 encounters). All candidate predation models included a term for wolf age to control for individual differences in hunting experience.

Given that wolves often hunted in groups, we examined how results from the best-fit models of attacking, selecting, and killing were influenced by group traits such as size (number of other wolves participating alongside the focal wolf) and composition (average predicted mass of other participating wolves). We separately tested the effects of these variables in each best-fit model for a subset of observations that included this information. Neither group size nor average group mass altered how an individual's mass affected its performance of each task.

Finally, we calculated the net effect of body mass on overall hunting success, i.e., $P$ (kill $\mid$ encounter), as the product of its effect on the outcome of each predatory task. Specifically, we multiplied the population-averaged fitted values and associated pointwise $95 \%$ confidence intervals calculated from the best-fit models of attacking, selecting and killing, such that each task contributed equally to overall success. We calculated the overall effect of size in this way to determine if larger size provided a net predatory benefit across the different tasks. A consequence of this approach is that it probably exaggerated variability in overall success owing to positive correlations between the different tasks. The confidence intervals for overall success were therefore conservative.

\section{Results}

A growth model including a breakpoint at $0 \cdot 75$-years for males and females, a breakpoint at $4 \cdot 75$-years for males only, and interactions between sex and the first and second splines provided the best fit to the body mass data (Table 1). Significant statistical differences between male and female growth reflected
Table 1. Best-fit GLMM model for the effects of age and sex on wolf body mass $(\mathrm{kg})$. Age_1 is the slope before age 0.75 years, and age_2 and age_ 3 are the slopes after 0.75 and 4.75 years, respectively. age_3 applies to males only. Male is the reference category for the sex parameter. Model selection results are included as Table S1

\begin{tabular}{|c|c|c|c|c|c|c|}
\hline \multirow{2}{*}{$\frac{\text { Parameter }}{\text { constant }}$} & \multirow{2}{*}{$\frac{\beta}{-0 \cdot 41}$} & \multirow{2}{*}{$\begin{array}{l}\text { SE } \\
1 \cdot 72\end{array}$} & \multirow{2}{*}{$\begin{array}{l}z \\
-0 \cdot 24\end{array}$} & \multirow{2}{*}{$\begin{aligned} P \\
0 \cdot 811\end{aligned}$} & \multicolumn{2}{|c|}{$\begin{array}{l}95 \% \text { confidence } \\
\text { interval }\end{array}$} \\
\hline & & & & & $-3 \cdot 78$ & $2 \cdot 96$ \\
\hline age_1 & $50 \cdot 80$ & $2 \cdot 55$ & $19 \cdot 93$ & $<0.001$ & $45 \cdot 80$ & $55 \cdot 79$ \\
\hline age_2 & $1 \cdot 28$ & $0 \cdot 30$ & $4 \cdot 28$ & $<0.001$ & $0 \cdot 69$ & $1 \cdot 87$ \\
\hline age_3 & $-1 \cdot 24$ & $0 \cdot 60$ & $-2 \cdot 08$ & 0.038 & $-2 \cdot 41$ & $-0 \cdot 07$ \\
\hline sex & $-3 \cdot 16$ & $2 \cdot 32$ & $-1 \cdot 36$ & $0 \cdot 174$ & $-7 \cdot 71$ & $1 \cdot 40$ \\
\hline age_1 $1 \times$ sex & $12 \cdot 21$ & $3 \cdot 47$ & 3.52 & $<0.001$ & $5 \cdot 41$ & $19 \cdot 01$ \\
\hline age_2 $\times$ sex & $1 \cdot 46$ & $0 \cdot 44$ & $3 \cdot 32$ & 0.001 & $0 \cdot 60$ & $2 \cdot 32$ \\
\hline
\end{tabular}
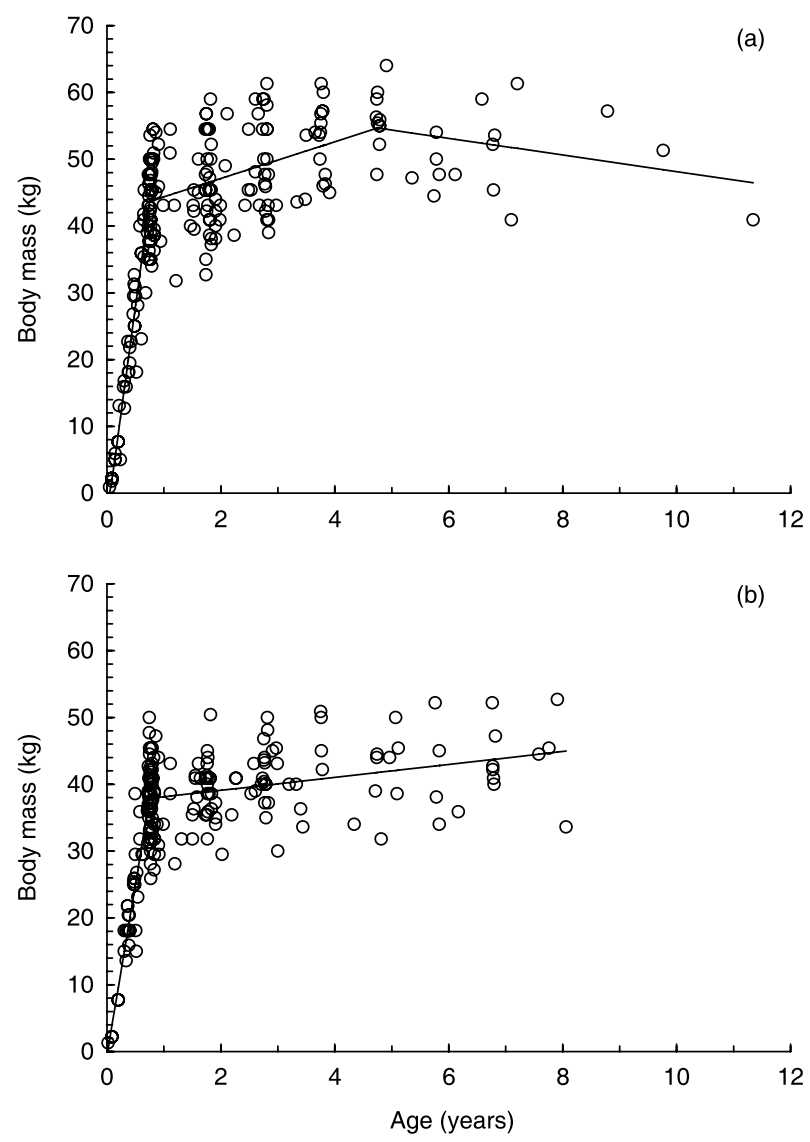

Fig. 1. Observed body mass for male (a) and female (b) wolves versus age with population-averaged fitted value lines from the best-fit mixed effects growth model (Table 1).

more rapid male growth before and after $0 \cdot 75$-years, and a decline in male size following $4 \cdot 75$-years (Fig. 1). Body mass was correlated with chest girth $\left(r^{2}=0.53, P<0 \cdot 001\right)$, body length $\left(r^{2}=0 \cdot 45, P<0 \cdot 001\right)$ and height $\left(r^{2}=0 \cdot 31, P<0 \cdot 001\right)$, so we considered it to be a valid index of overall size.

The effect of size on predatory ability varied among the predatory tasks in a manner consistent with our predictions. 

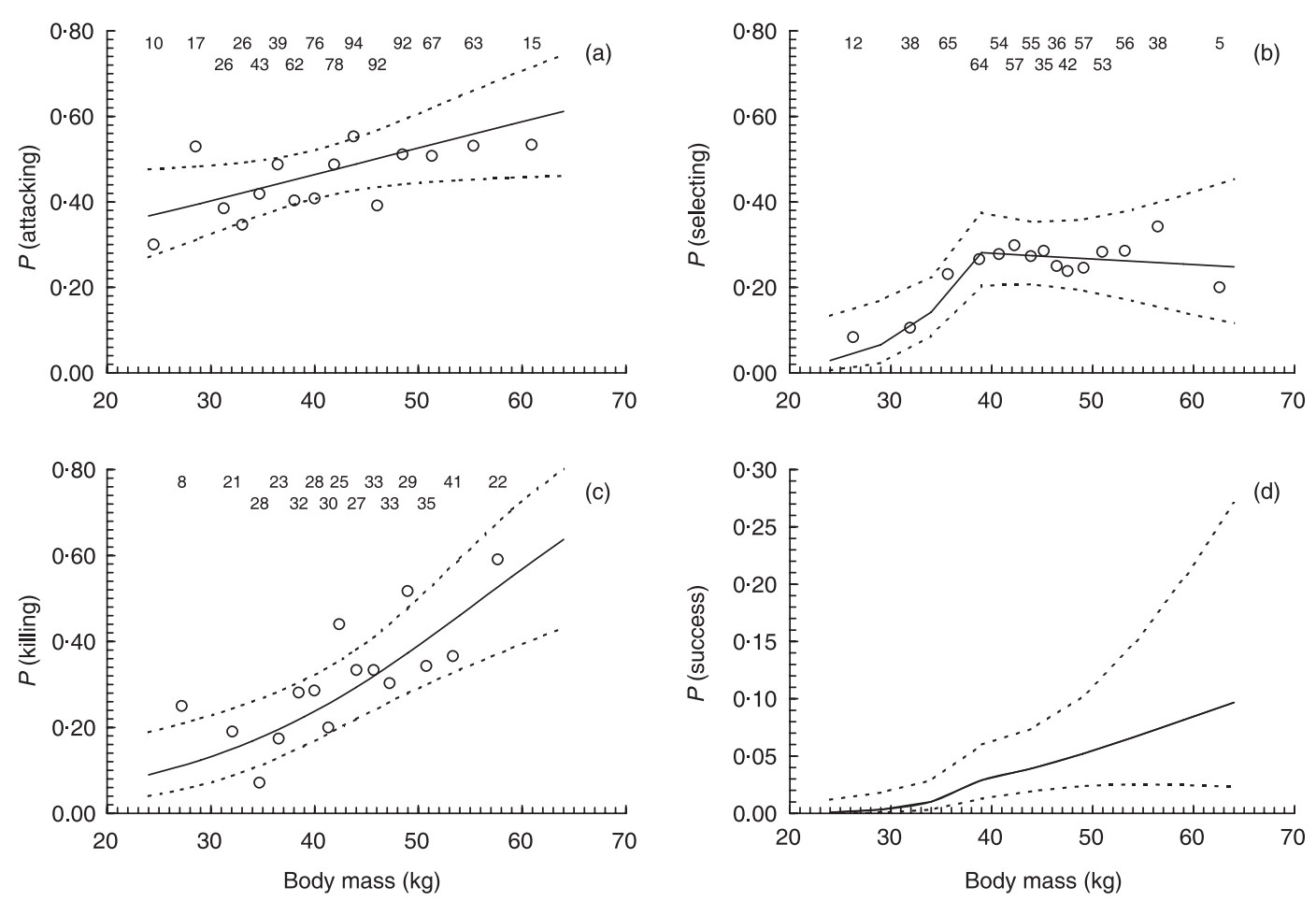

Fig. 2. Effects of wolf body mass (kilogram) on the ability of individual wolves to attack (a), select (b), and kill elk (c). Solid lines are populationaveraged fitted value lines from the best-fit mixed effects predation models (Table 2) with dotted lines indicating pointwise $95 \%$ confidence intervals, and points are observed frequencies for each of 15 body mass categories determined via $k$-means cluster analysis with sample size indicated above each point. Analyses were performed on the raw binary data and not the illustrated points which are provided as a visual aid. The product of the fitted value lines and associated pointwise $95 \%$ confidence intervals in (a), (b), and (c), representing the overall probability of success given an elk encounter and thus the net effect of body mass on predatory ability, is shown in (d).

Whereas the best models of attacking and killing described a linear relation between size and ability, the best model of selecting was curvilinear (Table S2). The fit of the top model of selecting, which included a polynomial term for size, was 3.4 times $\left(\mathrm{AIC}_{c}\right.$ weights $\left.=0 \cdot 57 / 0 \cdot 17\right)$ better than a similar model that included only a main effect for size. Both attacking and killing ability improved with size (Fig. 2a,c), but the magnitude of a $1-\mathrm{kg}$ size increase was $3 \cdot 5$ times $(0 \cdot 07 / 0 \cdot 02)$ greater for killing than it was for attacking (Table 2a,c).

The curvilinear relation between size and selecting pointed to a threshold beyond which further size increases failed to improve performance. $\mathrm{AIC}_{c}$ indicated that a spline model including a breakpoint at $39 \mathrm{~kg}$ provided a fit to the data nearly four times $\left(\mathrm{AIC}_{c}\right.$ weights $\left.=0 \cdot 15 / 0 \cdot 04\right)$ better than the polynomial model (Table S3). But although this was the best scoring of the candidate spline models, models with breakpoints $35-38 \mathrm{~kg}$ and $40-42 \mathrm{~kg}$ also scored well $\left(\Delta \mathrm{AIC}_{c} \leq 2 \cdot 00\right.$; Table S3), indicating that a plausible size threshold ranged between $35-42 \mathrm{~kg}$. Assuming the model with a breakpoint at $39 \mathrm{~kg}$ best explained the effects of size on selecting, exponentiating this model's coefficients (Table $2 b$ ) revealed that an individual's odds of selecting improved by $19 \%$ for each $1 \mathrm{~kg}$ increase in size $<39 \mathrm{~kg}$, and diminished by $1 \%$ for each $1 \mathrm{~kg}$ increase $>39 \mathrm{~kg}$ (Fig. 2b). The slope of the decline phase, however, was not significantly different from 0 (Table $2 b$ ). This slope remained negative even when the 5 observations
Table 2. Best-fit GZLMM models for the effects of body mass (kilogram) on the ability of an individual wolf to attack (a), select (b), and kill elk (c). In model (b) mass_1 is the slope before $39 \mathrm{~kg}$, and mass_2 is the slope after $39 \mathrm{~kg}$. Model selection results are included as Tables S2-S3

\begin{tabular}{|c|c|c|c|c|c|c|}
\hline \multirow{2}{*}{$\begin{array}{l}\text { Parameter } \\
\text { (a) attacking }\end{array}$} & \multirow[t]{2}{*}{$\beta$} & \multirow[t]{2}{*}{$\mathrm{SE}$} & \multirow[t]{2}{*}{$z$} & \multirow[t]{2}{*}{$P$} & \multicolumn{2}{|c|}{$\begin{array}{l}95 \% \text { confidence } \\
\text { interval }\end{array}$} \\
\hline & & & & & & \\
\hline constant & $-1 \cdot 08$ & $0 \cdot 50$ & $-2 \cdot 17$ & $0 \cdot 030$ & $-2 \cdot 05$ & $-0 \cdot 11$ \\
\hline mass & $0 \cdot 02$ & $0 \cdot 01$ & $2 \cdot 05$ & $0 \cdot 040$ & $<0.01$ & 0.05 \\
\hline age & $-0 \cdot 07$ & $0 \cdot 04$ & $-1 \cdot 68$ & $0 \cdot 093$ & $-0 \cdot 15$ & $0 \cdot 01$ \\
\hline (b) selecting & & & & & & \\
\hline constant & $-7 \cdot 57$ & $2 \cdot 28$ & $-3 \cdot 32$ & 0.001 & $-12 \cdot 03$ & $-3 \cdot 10$ \\
\hline mass_1 & $0 \cdot 17$ & 0.06 & $2 \cdot 83$ & 0.005 & $0 \cdot 05$ & $0 \cdot 29$ \\
\hline mass_2 & $-0 \cdot 01$ & 0.02 & $-0 \cdot 31$ & 0.755 & $-0 \cdot 05$ & $0 \cdot 04$ \\
\hline age & $-0 \cdot 08$ & 0.06 & $-1 \cdot 25$ & $0 \cdot 211$ & $-0 \cdot 20$ & 0.04 \\
\hline (c) killing & & & & & & \\
\hline constant & $-4 \cdot 02$ & $0 \cdot 87$ & $-4 \cdot 64$ & $<0.001$ & $-5 \cdot 71$ & $-2 \cdot 32$ \\
\hline mass & $0 \cdot 07$ & 0.02 & 3.75 & $<0.001$ & 0.03 & $0 \cdot 11$ \\
\hline age & -0.03 & 0.06 & $-0 \cdot 50$ & 0.616 & $-0 \cdot 16$ & 0.09 \\
\hline
\end{tabular}

$>60 \mathrm{~kg}$ that comprised the last point in Fig. $2 \mathrm{~b}$ were excluded from the analysis $(\beta=-0.0035, \mathrm{SE}=0.02, P=0.875)$.

Despite the cap on improvements in selecting ability, the net predatory effect of size, calculated as the product of the population-averaged fitted values estimated from the best-fit 
models of attacking, selecting, and killing (Table 2) and illustrated in Fig. 2a-c, was strongly positive (Fig. 2d). Thus, larger size yielded, on average, a net predatory benefit to individual wolves. Nevertheless, the lower $95 \%$ confidence interval of the net result, calculated as the product of the lower confidence intervals associated with each set of populationaveraged fitted values, indicated that a slight decline in overall performance at larger sizes was not implausible.

An interesting outcome of this analysis was that a wolf's sex, when considered alongside its mass, was unimportant in determining its predatory performance. A term for sex was included in some of the candidate predation models (Table S2) but none of these were among the set of best models (Table 2). To assess whether sexual dimorphism in size accounted for any intersexual difference in performance we included a term for sex in each of the best predation models (Table 2) and compared its effect on task performance between models with and without mass. In models including mass, males were statistically no more likely than females to attack (odds ratio $(\mathrm{OR})=1 \cdot 24 \pm 0 \cdot 26, P=0 \cdot 32)$, select $(\mathrm{OR}=$ $1 \cdot 24 \pm 0 \cdot 38, P=0 \cdot 50)$ or kill $(\mathrm{OR}=0 \cdot 88 \pm 0 \cdot 30, P=0 \cdot 71)$. By contrast, in models excluding mass, males appeared to outperform females in attacking $(\mathrm{OR}=1.42 \pm 0 \cdot 27, P=0 \cdot 06)$, selecting $(\mathrm{OR}=1 \cdot 43 \pm 0 \cdot 40, P=0 \cdot 20)$, and killing $(\mathrm{OR}=1.78$ $\pm 0 \cdot 50, P=0 \cdot 04)$.

\section{Discussion}

Studies of ontogenetic change in vertebrate foraging performance are rare (reviewed by Herrel \& Gibb 2006), and to the best of our knowledge this is the first study to examine the effects of physical development on the predatory ability of a free-living carnivore. Relating growth to foraging performance in wild carnivores is challenging because they are usually difficult to observe in nature and their size is not easily measured immediately before or after a predator-prey interaction. We observed wolves hunt elk in YNP because they often did so during daylight hours in open habitats, and we estimated their size from a sex-specific growth model derived from body mass measurements recorded during concurrent monitoring of the population. An interesting result from the growth model was that male body mass declined after age $4 \cdot 75$, whereas female mass continued to increase. This might reflect a sex difference in the rate of aging related to intense intrasexual competition between males that causes weak selection for longevity in males relative to females (Clutton-Brock \& Isvaran 2007). Similar declines in male mass have been reported in wolves elsewhere (Mech 2006) and in wild chimpanzees (Pusey et al. 2005).

After controlling for differences in hunting experience, our results indicate that as wolves grew larger, their ability to perform different predatory tasks varied according to the biomechanical demands of each task. Selecting required burst acceleration (force/mass) to single out elk (MacNulty et al. 2007), and at smaller sizes ( $<39 \mathrm{~kg}$ ) selecting likely improved with size due to increased muscle mass (force) and limb length (Garland \& Janis 1993). Limb growth, as indexed by shoulder height, approached an asymptote near $27 \mathrm{~kg}$ (Tables S4-S5; Fig. S1), and so final improvements before selecting level-off at $39 \mathrm{~kg}$ probably reflected added muscle. If wolves continued to add muscle after $39 \mathrm{~kg}$, then their ability to accelerate and select elk may have been checked by reductions in muscle shortening velocity with increasing size (Rome, Sosnicki \& Goble 1990) and/or limits in the stress tolerance of the limb skeleton (Iriarte-Diaz 2002). However, experimental studies of dogs (Canis lupus familiaris) indicate that muscle mass can decline or remain constant even as total mass increases owing to added fat mass (Lauten et al. 2001; Kealy et al. 2002; Speakman, van Acker \& Harper 2003), and these changes have been linked to reduced sprinting performance in racing dogs (Hill et al. 2005). A similar shift in wolf body composition at $39 \mathrm{~kg}$ might therefore also explain why selecting levelled off, and the sharp decline in growth rates near this size (Fig. 1; females: $38 \mathrm{~kg}$; males: $44 \mathrm{~kg}$ ) may reflect such a change.

Assuming larger wolves were more muscular than smaller ones, our finding that killing ability improved markedly with size is consistent with the idea that effective prey handling requires substantial muscular force. However, if muscle mass did not increase continuously with size as outlined above, then our results would suggest that killing depends on sheer mass rather than strength alone. This would not be surprising given that wolves, like other cursorial carnivores (e.g., Lycaon pictus, Crocuta crocuta), lack muscular forelimbs and so rely on their whole weight to topple a large prey after securing a firm bite, which undoubtedly requires strong jaws (Binder \& Van Valkenburgh 2000). Thus, once maximum jaw muscle mass is attained, continued size-related improvement in killing ability may depend entirely on increases in total mass.

Compared to selecting and killing, the task of attacking elk was not physically demanding. Wolves required neither great strength nor quick acceleration to complete the transition from walking/trotting towards elk to running/lunging at them. Larger wolves were therefore only marginally better attackers compared to smaller wolves, possibly because larger wolves were less intimidated by elk, which were comparatively large (e.g., adult female elk $=175-275 \mathrm{~kg}$; Cook, Cook \& Mech 2004).

Although the difference in the effect of size on selecting and killing was consistent with a size-mediated trade-off between pursuing and handling prey, the decline in selecting after $39 \mathrm{~kg}$ was not statistically significant, indicating that selecting was effectively constant at larger sizes. This implies that wolves were able to simultaneously maximize selecting and killing ability as they increased in size despite the contrasting effects of size on locomotor and handling performance. This finding is surprising given that optimal performance in two functions is not expected to evolve when they require opposing biomechanical or physiological adaptations (Stearns 1992). Perhaps larger wolves improved killing without sacrificing selecting because the biomechanical requirements of the two tasks were not too dissimilar. Alternatively, other unmeasured aspects of pursuit ability, such as time to exhaustion(Brzezinksa, Kaciuba-Uscilko \& Nazar 1980), might have proved more sensitive to size increase. 
Absent a major trade-off between selecting and killing elk, individual wolves gained, on average, a net predatory benefit from larger size. This confirms the generalization that vertebrate foraging performance scales positively with body size (Herrel \& Gibb 2006; Vincent et al. 2007) despite variation in the effect of size on different phases of performance. This variation, however, does demonstrate how conclusions about the strength of the relation between size and performance can differ depending upon the phase that is measured. Our results also show that the effect of size on net performance is quite different than its effect on any one phase. This is relevant to evaluating the selective advantage of size for predation, given that the selective value of a predatory trait is necessarily a function of its net effect on the final outcome of a predator-prey interaction (i.e., kill or no kill). Had we measured only killing behaviour, as many studies do, larger size would have appeared overall more advantageous than it actually was.

Evidence that predatory performance increases with size in a wild carnivore is notable because it provides the first direct support for the hypothesis that improved predatory ability favours the evolution of large size in carnivores (Van Valkenburgh et al. 2004). An important consequence of larger size is that it increases energetic requirements and necessitates feeding on larger prey (Carbone et al. 1999, 2007), which tend to be more difficult to kill than smaller prey (e.g., Funston et al. 1998, 2001; Smith et al. 2000). Our results suggest that improved predatory ability (arising from size-related increase in certain physical capacities) may allow larger carnivores to overcome the defences of larger prey and thereby switch from smaller to larger prey (sensu Gittleman 1985). Evidence that males of several sexually dimorphic species can take bigger prey than females (Caro \& FitzGibbon 1992; Funston et al. 1998, 2001; Radloff \& Du Toit 2004; Sand et al. 2006) along with our finding that males outperformed females because they were themselves bigger, supports the idea that bigger carnivores take bigger prey because they are overall better hunters. Thus, the well-known relationship between carnivore body weight and prey size is likely the joint result of size-related increase in energetic costs and predatory performance.

On the other hand, our results do not completely rule out the possibility that bigger carnivores are sometimes overall worse hunters. Specifically, the right tail of the lower 95\% confidence interval for the effect of size on overall hunting success (Fig. 2d) indicates that wolves near $54 \mathrm{~kg}$ may occasionally outperform larger wolves owing to the impact of large size on selecting. This result, although tenuous, is consistent with data showing that male lions $(188 \mathrm{~kg})$ are overall worse hunters of fleet-footed prey compared to smallersized female lions (124 kg) (Funston et al. 1998, 2001). Taken together, these results suggest that net predatory performance will decrease with size when prey are substantially more difficult to pursue than handle. Additional evidence is obviously necessary to verify this pattern, and we believe further studies are warranted because an inverse relationship between size and performance during hunts of highly cursorial prey has important implications for understanding the ecology and evolution of carnivores.
For example, poor success hunting cursorial prey may narrow the dietary range of larger carnivores to larger prey given that cursorial prey tend to be smaller $(<119 \mathrm{~kg}$; Garland 1983). Larger carnivores are generally thought to exploit a prey size range that is broader than that of smaller carnivores (Sinclair et al. 2003; Radloff \& Du Toit 2004), but long-term records from Kruger National Park, South Africa, indicate that the largest carnivores (e.g., lions) kill mainly the largest prey (> $100 \mathrm{~kg}$; see Fig. 7 in Owen-Smith \& Mills 2008). Although preference for large prey is surely influenced by the energetic constraints of large size (Carbone et al. 1999, 2007), evidence that larger carnivores such as lions are poor hunters of smaller prey (Elliot, Cowan \& Holling 1977; Funston et al. 1998, 2001) suggests that dietary range may also be shaped by size-related functional constraints.

A related consequence of these constraints is that they might limit the evolution of larger size. This may arise from directional selection favouring decreased size or from increased vulnerability to extinction. The former is evidenced by morphological data showing that carnivores adapted to running - as indicated by elbow joints that allow only fore-aft movements with minimal supination - rarely reach $100 \mathrm{~kg}$, whereas carnivores adapted to grappling (maximal supination) are typically $\geq 100 \mathrm{~kg}$ (Andersson \& Werdelin 2003). Interestingly, $100 \mathrm{~kg}$ is near the size at which the absolute maximum running speed of carnivores starts declining (Garland 1983). And if poor locomotor performance narrows the range of potential prey to bigger, slower-moving species, extinction may ultimately prevent carnivores from evolving towards larger size given that dietary specialization elevates extinction risk (Van Valkenburgh et al. 2004). For example, the demise of Panthera atrox and other large North American carnivores during the mega-herbivore extinctions of the late Pleistocene may have been linked, in part, to their inability to switch to smaller, faster prey (Van Valkenburgh \& Hertel 1993).

\section{Acknowledgements}

We thank the YNP wolf project staff (D. Guernsey, D. Stahler) and winter study volunteers for field assistance, and R. Stradley and personnel from Hawkins and Powers, Inc., and Central Copters, Inc., for safe piloting. C. Packer, B. Van Valkenburgh, and J. Vucetich provided valuable comments on an earlier version of the manuscript. Research was supported by Canon USA, National Geographic Society, National Science Foundation (DEB-0613730), U.S. Geological Survey, and Yellowstone Park Foundation.

\section{References}

Andersson, K. \& Werdelin, L. (2003) The evolution of cursorial carnivores in the Tertiary: implications of elbow-joint morphology. Proceedings of the Royal Society B: Biological Sciences (Supplement), 270, S163-S165.

Bangs, E.E. \& Fritts, S.H. (1996) Reintroducing the gray wolf to central Idaho and Yellowstone National Park. Wildlife Society Bulletin, 24, 402 413 .

Biewener, A.A. (2003) Animal Locomotion. Oxford University Press, Oxford, UK. Binder, W.J. \& Van Valkenburgh, B. (2000) Development of bite strength and feeding behaviour in juvenile spotted hyenas (Crocuta crocuta). Journal of Zoology, London, 252, 273-283.

Brecko, J., Huyghe, K., Vanhooydonck, B., Herrel, A., Grbac, I. \& Van Damme, R. (2008) Functional and ecological relevance of intraspecific variation in body size and shape in the lizard Podarcis melisellensis (Lacertidae) Biological Journal of the Linnean Society, 94, 251-264. 
Brzezinksa, Z., Kaciuba-Uscilko, H. \& Nazar, K. (1980) Physiological responses to prolonged physical exercise in dogs. Archives Internationales de Physiologie et de Biochimie, 88, 285-291.

Burnham, K.P., \& Anderson, D.R. (2002) Model Selection and Multimodal Inference: A Practical Information-Theoretic Approach, 2nd edn. Springer, New York.

Carbone, C., Mace, G.M., Roberts, S.C. \& MacDonald, D.W. (1999) Energetic constraints on the diet of terrestrial carnivores. Nature, 402, 286-288.

Carbone, C., Teacher, A. \& Rowcliffe, J.M. (2007) The costs of carnivory. $P L o S$ Biology, 5, 1-6.

Caro, T.M. \& FitzGibbon, C.D. (1992) Large carnivores and their prey: the quick and the dead. Natural Enemies: The Population Biology of Predators, Parasites and Diseases (ed. M.J. Crawley), pp. 117-142. Blackwell Scientific Publications, Oxford, UK.

Clutton-Brock, T.H. \& Isvaran, K. (2007) Sex differences in ageing in natural populations of vertebrates. Proceedings of the Royal Society B: Biological Sciences, 274, 3097-3104.

Cook, R.C., Cook, J.G. \& Mech, L.D. (2004) Nutritional condition of northern Yellowstone elk. Journal of Mammalogy, 85, 714-722.

Dial, K.P., Greene, E. \& Irschick, D.J. (2008) Allometry of behaviour. Trends in Ecology \& Evolution, 23, 394-401

Elliot, J.P., Cowan, I.M. \& Holling, C.S. (1977) Prey capture by the African lion. Canadian Journal of Zoology, 55, 1811-1828.

Funston, P.J., Mills, M.G.L., Biggs, H.C. \& Richardson, P.R.K. (1998) Hunting by male lions: ecological influences and socioecological implications. Animal Behaviour, 56, 1333-1345.

Funston, P.J., Mills, M.G.L. \& Biggs, H.C. (2001) Factors affecting the hunting success of male and female lions in the Kruger National Park. Journal of Zoology, London, 253, 419-431.

Garland, T. (1983) The relation between maximal running speed and body mass in terrestrial mammals. Journal of Zoology, London, 199, 157-170.

Garland, T. \& Janis, C.M. (1993) Does metatarsal/femur ratio predict maximal running speed in cursorial mammals? Journal of Zoology, London, 229, 133-151.

Gipson, P.S., Ballard, W.B., Nowak, R.M. \& Mech, L.D. (2000) Accuracy and precision of estimating age of gray wolves by tooth wear. Journal of Wildlife Management, 64, 752-758.

Gittleman, J.L. (1985) Carnivore body size: ecological and taxonomic correlates. Oecologia, 67, 540-554.

Herrel, A. \& Gibb, A.C. (2006) Ontogeny of performance in vertebrates. Physiological and Biochemical Zoology, 79, 1-6.

Herrel, A. \& O'Reilly, J.C. (2006) Ontogenetic scaling of bite force in lizards and turtles. Physiological and Biochemical Zoology, 79, 31-42.

Hill, R.C., Lewis, D.D., Randell, S.C., Scott, K.C., Omori, M., Sundstrom, D.A., Jones, G.L., Speakman, J.R. \& Butterwick, R.F. (2005) Effect of mild restriction of food intake on the speed of racing greyhounds. American Journal of Veterinary Research, 66, 1065-1070.

Iriarte-Diaz, J. (2002) Differential scaling of locomotor performance in small and large terrestrial mammals. Journal of Experimental Biology, 205, 2897 2908.

Kealy, R.D, Lawler, D.F., Ballam, J.M., Mantz, S.L., Biery, D.N., Greeley, E.H., Lust, G., Segre, M., Smith, G.K. \& Stowe, H.D. (2002) Effects of diet restriction on life span and age-related changes in dogs. Journal of the American Veterinary Medical Association, 220, 1315-1320.

Kruuk, H. (1972) The Spotted Hyena. University of Chicago Press, Chicago, Illinois.

Lauten, S.D., Cox, N.R., Brawner, W.R. \& Baker, H.J. (2001) Use of dua energy $\mathrm{x}$-ray absorptiometry for noninvasive body composition measurements in clinically normal dogs. American Journal of Veterinary Research, 62, 1295-1301.

Lima, S.L. \& Dill, L.M. (1990) Behavioural decisions made under the risk of predation: a review and prospectus. Canadian Journal of Zoology, 68, 619640.

MacNulty, D.R., Mech, L.D. \& Smith, D.W. (2007) A proposed ethogram of large-carnivore predatory behaviour, exemplified by the wolf. Journal of Mammalogy, 88, 595-605.

Mech, L.D. (2006) Age-related body mass and reproductive measurements of gray wolves in Minnesota. Journal of Mammalogy, 87, 80-84.

Nilsson, P.A. \& Bronmark, C. (2000) Prey vulnerability to a gap-size limited predator: behavioural and morphological impacts on northern pike piscivory. Oikos, 88, 539-546.

Owen-Smith, N. \& Mills, M.G.L. (2008) Predator-prey size relationships in an African large-mammal food web. Journal of Animal Ecology, 77, 173-183.

Pusey, A.E., Oehlert, G.W., Williams, J.M. \& Goodall, J. (2005) Influence of ecological and social factors on body mass of wild chimpanzees. International Journal of Primatology, 26, 3-31.
Radloff, F.G.T. \& Du Toit, J.T. (2004) Large predators and their prey in a southern African savanna: a predator's size determines its prey size range. Journal of Animal Ecology, 73, 410-423.

Rome, L.C., Sosnicki, A.A. \& Goble, D.O. (1990) Maximum velocity of shortening of three fiber types from horse soleus muscle: implications for scaling with body size. Journal of Physiology, 431, 173-185.

Sand, H., Wikenros, C., Wabakken, P. \& Liberg, O. (2006) Effects of hunting group size, snow depth and age on the success of wolves hunting moose. Animal Behaviour, 78, 781-789.

Sinclair, A.R.E., Mduma, S. \& Brashares, J.S. (2003) Patterns of predation in a diverse predator-prey community. Nature, 425, 288-290.

Smith, D.W., Mech, L.D., Meagher, M., Clark, W.E., Jaffe, R., Phillips, M.K. \& Mack, J.A. (2000) Wolf-bison interactions in Yellowstone National Park. Journal of Mammalogy, 81, 1128-1135.

Smith, D.W., Drummer, T.D., Murphy, K.M., Guernsey, D.S. \& Evans, S.B. (2004) Winter prey selection and estimation of wolf kill rates in Yellowstone National Park, 1995-2000. Journal of Wildlife Management, 68, 153-166.

Speakman, J.R., van Acker, A. \& Harper, E.J. (2003) Age-related changes in the metabolism and body composition of three dog breeds and their relationship to life expectancy. Aging Cell, 2, 265-275.

Stearns, S.C. (1992) The Evolution of Life Histories. Oxford University Presss, Oxford, UK.

Van Ballenberghe, V. \& Mech, L.D. (1975) Weights, growth, and survival of timber wolf pups in Minnesota. Journal of Mammalogy, 56, 44-63.

Van Valkenburgh, B. \& Hertel, F. (1993) Tough times at La Brea: tooth breakage in large carnivores of the late Pleistocene. Science, 261, 456459

Van Valkenburgh, B., Wang, X.M. \& Damuth, J. (2004) Cope's rule, hypercarnivory, and extinction in North American canids. Science, 306, 101104.

Van Wassenbergh, S., Aerts, P. \& Herrel, A. (2005) Scaling of suction-feeding kinematics and dynamics in the African catfish, Clarias gariepinus. Journal of Experimental Biology, 208, 2103-2114.

Vincent, S.E., Moon, B.R., Herrel, A. \& Kley, N.J. (2007) Are ongenetic shifts in diet linked to shifts in feeding mechanics? Scaling of the feeding apparatus in the banded watersnake Nerodia fasciata. Journal of Experimental Biology, 210, 2057-2069.

Weiss, R.E. (2005) Modeling Longitudinal Data. Springer, New York.

Received 2 August 2008; accepted 9 December 2008

Handling Editor: Andrew Beckerman

\section{Supporting information}

Additional supporting information may be found in the online version of this article or on the following pages

Fig. S1. Observed shoulder height versus wolf body mass with fitted linear spline curve from Table S5.

Table S1. A priori candidate GLMM models for the effects of age and sex on wolf body mass

Table S2. A priori candidate GZLMM models for the effects of body mass on the ability of an individual wolf to attack, select, and kill elk

Table S3. A priori candidate GZLMM spline models for the effects of body mass on the ability of an individual wolf to select out an elk from a group

Table S4. A priori candidate SLR spline models for the association between wolf body mass and shoulder height

Table S5. Best-fit SLR model for the association between wolf body mass and shoulder height

Please note: Wiley-Blackwell are not responsible for the content or functionality of any supporting information supplied by the authors. Any queries (other than missing material) should be directed to the corresponding author for the article. 
Table S1. A priori candidate GLMM models for the effects of age (years) and sex on wolf body mass (kg) $(N=304$ wolves). Loglikelihood (LL), number of parameters $(K), \mathrm{AIC}_{\mathrm{c}}$, differences in $\mathrm{AIC}_{\mathrm{c}}$ compared to the best scoring model ( $\left.\triangle \mathrm{AIC}\right)$, and $\mathrm{AIC} \mathrm{c}_{\mathrm{c}}$ weights $\left(W_{\mathrm{i}}\right)$ are given for each model, $i$. The best model (i.e., $\left.\Delta \mathrm{AIC}=0\right)$ is in boldface.

\begin{tabular}{|c|c|c|c|c|c|}
\hline Model set & LL & K & $\mathrm{AIC}_{\mathrm{c}}$ & $\Delta \mathrm{AIC}_{\mathrm{c}}$ & $W_{\mathrm{i}}$ \\
\hline \multicolumn{6}{|l|}{ (a) breakpoints: none } \\
\hline age & -1579.8 & 3 & 3165.77 & 562.64 & 0.00 \\
\hline age + sex & -1565.7 & 4 & 3139.48 & 536.35 & 0.00 \\
\hline age + sex + age*sex & -1562.7 & 5 & 3135.60 & 532.47 & 0.00 \\
\hline \multicolumn{6}{|l|}{ (b) breakpoint: 0.75 -yrs } \\
\hline age_1 $1+$ age_2 & -1369.8 & 4 & 2747.81 & 144.68 & 0.00 \\
\hline age_1 + age_ $2+$ sex & -1318.2 & 5 & 2646.51 & 43.38 & 0.00 \\
\hline age_1 + age $\_2+$ sex + age_ $1 *$ sex & -1307.4 & 6 & 2627.16 & 24.02 & 0.00 \\
\hline age_1 + age_2 + sex + age_ $2 *$ sex & -1313.4 & 6 & 2638.99 & 35.86 & 0.00 \\
\hline age_1 $1+$ age_2 + sex + age_ $1 * \operatorname{sex}+$ age_ $2 *$ sex & -1305.7 & 7 & 2625.82 & 22.69 & 0.00 \\
\hline \multicolumn{6}{|l|}{ (c) breakpoints: 0.75-yrs, 3.75-yrs } \\
\hline age_1 + age_2+age_3 & -1360.7 & 5 & 2731.67 & 128.54 & 0.00 \\
\hline age_1 $1+$ age $\_2+$ age $\_3+$ sex & -1309.4 & 6 & 2631.12 & 27.99 & 0.00 \\
\hline age_1 + age $\_2+$ age $3+$ sex + age $\_1 * \operatorname{sex}$ & -1298.4 & 7 & 2611.19 & 8.06 & 0.01 \\
\hline age_1 + age $\_2+$ age_ $3+\operatorname{sex}+$ age $\_2 * \operatorname{sex}$ & -1301.2 & 7 & 2616.76 & 13.63 & 0.00 \\
\hline age_1 + age_ $2+$ age_ $3+$ sex + age_ $3 *$ sex & -1308.6 & 7 & 2631.54 & 28.41 & 0.00 \\
\hline
\end{tabular}


Table S1 Continued...

\begin{tabular}{|c|c|c|c|c|c|}
\hline Model set & LL & $K$ & $\mathrm{AIC}_{\mathrm{c}}$ & $\Delta \mathrm{AIC}_{\mathrm{c}}$ & $W_{\mathrm{i}}$ \\
\hline age_1 + age_2+age_3+ sex + age_ $1 * \operatorname{sex}+$ age_ $2 *$ sex & -1295.1 & 8 & 2606.65 & 3.52 & 0.07 \\
\hline age_1 + age_2 + age_ $3+$ sex + age_ $1 * \operatorname{sex}+$ age_ $3 *$ sex & -1298.1 & 8 & 2612.78 & 9.65 & 0.00 \\
\hline age_1 $1+$ age_ $2+$ age_ $3+$ sex + age_ $2 *$ sex + age_ $3 *$ sex & -1300.5 & 8 & 2617.51 & 14.38 & 0.00 \\
\hline age $11+$ age $22+$ age $\_3+$ sex + age $\_1 * \operatorname{sex}+$ age $22 *$ sex + age $\_3 *$ sex & -1294.7 & 9 & 2608.07 & 4.94 & 0.04 \\
\hline \multicolumn{6}{|l|}{ (d) breakpoints: 0.75 -yrs, 4.75-yrs } \\
\hline age_1 + age_2 + age_3 & -1361.6 & 5 & 2733.38 & 130.25 & 0.00 \\
\hline age_1 $1+$ age_ $2+$ age $3+$ sex & -1309.3 & 6 & 2630.94 & 27.81 & 0.00 \\
\hline age_1 $1+$ age_ $2+$ age_ $3+$ sex + age_ $1 *$ sex & -1298.1 & 7 & 2610.58 & 7.45 & 0.01 \\
\hline age_1 + age_2 + age_ $3+$ sex + age_ $2 *$ sex & -1300.9 & 7 & 2616.13 & 12.99 & 0.00 \\
\hline age_1 + age_ $2+$ age_ $3+$ sex + age_ $3 *$ sex & -1309.1 & 7 & 2632.64 & 29.50 & 0.00 \\
\hline age_1 $1+$ age_ $2+$ age_ $3+$ sex + age_ $1 * \operatorname{sex}+$ age_ $2 *$ sex & -1294.4 & 8 & 2605.25 & 2.12 & 0.15 \\
\hline age_1 + age_2 + age_ $3+$ sex + age_ $1 * \operatorname{sex}+$ age_ $3 *$ sex & -1298.1 & 8 & 2612.67 & 9.54 & 0.00 \\
\hline age_1 + age $\_2+$ age $\_3+$ sex + age $\_2 *$ sex + age_ $3 *$ sex & -1299.2 & 8 & 2614.88 & 11.75 & 0.00 \\
\hline age_1 + age_2 + age $3+$ sex + age $\_1 * \operatorname{sex}+$ age_ $2 * \operatorname{sex}+$ age $3 *$ sex & -1293.3 & 9 & 2605.11 & 1.98 & 0.16 \\
\hline \multicolumn{6}{|l|}{ (e) breakpoints: $0.75-y r s, 5.75-y r s$} \\
\hline age_1 + age_2 + age_3 & -1364.9 & 5 & 2739.92 & 136.78 & 0.00 \\
\hline age $\_1+$ age $\_2+$ age $\_3+$ sex & -1312.0 & 6 & 2636.29 & 33.15 & 0.00 \\
\hline age_1 $1+$ age_ $2+$ age_ $3+$ sex + age_ $1 *$ sex & -1300.8 & 7 & 2615.91 & 12.78 & 0.00 \\
\hline
\end{tabular}


Table S1: Continued...

\begin{tabular}{|c|c|c|c|c|c|}
\hline Model set & LL & $K$ & $\mathrm{AIC}_{\mathrm{c}}$ & $\Delta \mathrm{AIC}_{\mathrm{c}}$ & $W_{\mathrm{i}}$ \\
\hline age_1 + age_2 + age_ $3+$ sex + age_ $2 *$ sex & -1304.1 & 7 & 2622.55 & 19.42 & 0.00 \\
\hline age_1 + age $\_2+$ age_ $3+$ sex + age_ $3 *$ sex & -1311.8 & 7 & 2638.02 & 34.89 & 0.00 \\
\hline age_1 $1+$ age_ $2+$ age_ $3+$ sex + age_ $1 *$ sex + age_ $2 *$ sex & -1297.2 & 8 & 2610.96 & 7.83 & 0.01 \\
\hline age_ $1+$ age_ $2+$ age $3+$ sex + age_ $1 * \operatorname{sex}+$ age_ $3 *$ sex & -1300.7 & 8 & 2617.96 & 14.83 & 0.00 \\
\hline age_1 + age_2 + age_ $3+$ sex + age $\_2 * \operatorname{sex}+$ age_ $3 *$ sex & -1303.1 & 8 & 2622.64 & 19.50 & 0.00 \\
\hline age_1 $1+$ age_2 + age_ $3+$ sex + age_ $1 * \operatorname{sex}+$ age_ $2 * \operatorname{sex}+$ age_ $3 * \operatorname{sex}$ & -1296.6 & 9 & 2611.84 & 8.71 & 0.01 \\
\hline \multicolumn{6}{|l|}{ (f) breakpoints: 0.75 -yrs (males and females), 3.75-yrs (males only) } \\
\hline age_1 + age_2 + age_ 3 & -1358.5 & 5 & 2727.16 & 124.03 & 0.00 \\
\hline age_1 + age_ $2+$ age_ $3+$ sex & -1309.3 & 6 & 2630.96 & 27.83 & 0.00 \\
\hline age_1 + age_2 + age_ $3+$ sex + age_ $1 *$ sex & -1298.5 & 7 & 2611.32 & 8.19 & 0.01 \\
\hline age_1 + age $22+$ age_ $3+$ sex + age_ $2 *$ sex & -1300.8 & 7 & 2616.05 & 12.92 & 0.00 \\
\hline age $\_1+$ age $\_2+$ age $\_3+$ sex + age $\_1 * \operatorname{sex}+$ age $\_2 *$ sex & -1294.9 & 8 & 2606.21 & 3.07 & 0.09 \\
\hline \multicolumn{6}{|l|}{ (g) breakpoints: 0.75 -yrs (males and females), 4.75-yrs (males only) } \\
\hline age_1+age_2 + age_3 & -1362.4 & 5 & 2735.05 & 131.92 & 0.00 \\
\hline age $11+$ age $\_2+$ age $33+$ sex & -1310.2 & 6 & 2632.68 & 29.54 & 0.00 \\
\hline age_1 $1+$ age_ $2+$ age $3+$ sex + age $\_1 * \operatorname{sex}$ & -1298.7 & 7 & 2611.84 & 8.71 & 0.01 \\
\hline age_1 + age_2 + age_ $3+$ sex + age_ $2 *$ sex & -1299.4 & 7 & 2613.24 & 10.11 & 0.00 \\
\hline age_1 + age_2 + age_3 + sex + age_1*sex + age_2*sex & -1293.3 & 8 & 2603.13 & 0.00 & 0.42 \\
\hline
\end{tabular}


Table S1: Continued...

\begin{tabular}{|c|c|c|c|c|c|}
\hline Model set & LL & $K$ & $\mathrm{AIC}_{\mathrm{c}}$ & $\Delta \mathrm{AIC}_{\mathrm{c}}$ & $W_{\mathrm{i}}$ \\
\hline \multicolumn{6}{|c|}{ (h) breakpoints: 0.75 -yrs (males and females), 5.75-yrs (males only) } \\
\hline age_1 + age_2 + age_3 & -1365.7 & 5 & 2741.67 & 138.54 & 0.00 \\
\hline age_1 + age_ $2+$ age_ $3+$ sex & -1312.8 & 6 & 2637.91 & 34.78 & 0.00 \\
\hline age_1 + age_2 + age_ $3+$ sex + age_ $1 *$ sex & -1301.4 & 7 & 2617.22 & 14.09 & 0.00 \\
\hline age_1 + age_2 + age_ $3+$ sex + age_ $2 *$ sex & -1303.1 & 7 & 2620.62 & 17.49 & 0.00 \\
\hline age_1 $1+$ age_ $2+$ age_ $3+$ sex + age_ $1 *$ sex + age_ $2 *$ sex & -1296.6 & 8 & 2609.72 & 6.59 & 0.02 \\
\hline
\end{tabular}


Table S2. A priori candidate GZLMM models for the effects of body mass $(\mathrm{kg})$ on the ability of an individual wolf to attack (a), select (b), and kill elk (c). Log-likelihood (LL), number of parameters $(K), \mathrm{AIC}_{\mathrm{c}}$, differences in $\mathrm{AIC}_{\mathrm{c}}$ compared to the best scoring model $(\triangle \mathrm{AIC})$, and $\mathrm{AIC}_{\mathrm{c}}$ weights $\left(W_{\mathrm{i}}\right)$ are given for each model. The best model (i.e., $\left.\Delta \mathrm{AIC}=0\right)$ for each predatory task is in boldface.

\begin{tabular}{|c|c|c|c|c|c|}
\hline Model set & LL & K & $\mathrm{AIC}_{\mathrm{c}}$ & $\Delta \mathrm{AIC}_{\mathrm{c}}$ & $W_{\mathrm{i}}$ \\
\hline \multicolumn{6}{|l|}{ (a) attacking } \\
\hline mass + age & -546.8 & 4 & 1102.13 & 0.00 & 0.49 \\
\hline mass + age + sex & -546.3 & 5 & 1103.38 & 1.25 & 0.26 \\
\hline mass + mass $^{2}+$ age & -546.8 & 5 & 1104.35 & 2.23 & 0.17 \\
\hline mass + mass $^{2}+$ age + sex & -546.3 & 6 & 1105.68 & 3.55 & 0.08 \\
\hline \multicolumn{6}{|l|}{ (b) selecting } \\
\hline mass + age & -371.6 & 4 & 751.81 & 2.39 & 0.17 \\
\hline mass + age + sex & -371.5 & 5 & 753.79 & 4.37 & 0.06 \\
\hline mass + mass $^{2}+$ age & -369.3 & 5 & 749.42 & $\mathbf{0 . 0 0}$ & 0.57 \\
\hline mass + mass $^{2}+$ age + sex & -369.2 & 6 & 751.50 & 2.08 & 0.20 \\
\hline \multicolumn{6}{|l|}{ (c) killing } \\
\hline mass + age & -248.6 & 4 & 505.75 & 0.00 & 0.55 \\
\hline mass + age + sex & -248.5 & 5 & 507.91 & 2.16 & 0.19 \\
\hline mass + mass $^{2}+$ age & -248.4 & 5 & 507.77 & 2.02 & 0.20 \\
\hline mass + mass $^{2}+$ age + sex & -248.4 & 6 & 510.02 & 4.27 & 0.06 \\
\hline
\end{tabular}


Table S3. A priori candidate GZLMM spline models for the effects of body mass (kg) on the ability of an individual wolf to select out an elk from a group. Log-likelihood (LL), number of parameters $(K), \mathrm{AIC}_{\mathrm{c}}$, differences in $\mathrm{AIC}_{\mathrm{c}}$ compared to the best scoring model $(\triangle \mathrm{AIC})$, and $\mathrm{AIC}_{\mathrm{c}}$ weights $\left(W_{\mathrm{i}}\right)$ are given for each model. The best model (i.e., $\left.\Delta \mathrm{AIC}=0\right)$ is in boldface, and the best model from Table $2 \mathrm{~b}$ is included for comparison.

\begin{tabular}{|c|c|c|c|c|c|}
\hline Model (breakpoint-kg) & LL & $K$ & $\mathrm{AIC}_{\mathrm{c}}$ & $\Delta \mathrm{AIC}_{\mathrm{c}}$ & $W_{i}$ \\
\hline mass + mass $^{2}+$ age & -369.3 & 5 & 749.42 & 2.68 & 0.04 \\
\hline mass_1 + mass_2 + age (34) & -369.3 & 5 & 749.48 & 2.73 & 0.04 \\
\hline mass_1 + mass_2 + age $(35)$ & -368.9 & 5 & 748.56 & 1.82 & 0.06 \\
\hline mass_1 + mass_2 + age (36) & -368.4 & 5 & 747.65 & 0.90 & 0.09 \\
\hline mass_1 + mass_2 + age $(37)$ & -368.1 & 5 & 746.99 & 0.24 & 0.13 \\
\hline mass_1 + mass_2 + age $(38)$ & -368.1 & 5 & 747.05 & 0.31 & 0.13 \\
\hline mass_1 + mass_2 + age (39) & -368.0 & 5 & 746.74 & 0.00 & 0.15 \\
\hline mass_1 + mass_2 + age $(40)$ & -368.1 & 5 & 746.93 & 0.18 & 0.14 \\
\hline mass_1 + mass_2 + age $(41)$ & -368.5 & 5 & 747.79 & 1.05 & 0.09 \\
\hline mass_1 + mass_2 + age $(42)$ & -368.8 & 5 & 748.44 & 1.69 & 0.06 \\
\hline mass_1 + mass_2 + age $(43)$ & -369.3 & 5 & 749.36 & 2.62 & 0.05 \\
\hline mass_1 + mass_2 + age $(44)$ & -369.8 & 5 & 750.34 & 3.60 & 0.02 \\
\hline
\end{tabular}


Table S4: A priori candidate simple linear regression (SLR) spline models for the association between wolf body mass $(\mathrm{kg})$ and shoulder height $(\mathrm{cm})(N=204$ wolves $)$. A non-spline model is included for comparison. Log-likelihood (LL), number of parameters $(K), \mathrm{AIC}_{\mathrm{c}}$, difference in $\mathrm{AIC}_{\mathrm{c}}$ compared to the best scoring model $(\triangle \mathrm{AIC})$, and $\mathrm{AIC}_{\mathrm{c}}$ weight $\left(W_{\mathrm{i}}\right)$ are given for each model. Numbers in parentheses indicate the location of the breakpoint for each model. The best model (i.e., $\triangle \mathrm{AIC}=0$ ) is in boldface.

\begin{tabular}{|c|c|c|c|c|c|}
\hline Model (breakpoint-kg) & LL & $K$ & $\mathrm{AIC}_{\mathrm{c}}$ & $\Delta \mathrm{AIC}_{\mathrm{c}}$ & $W_{\mathrm{i}}$ \\
\hline mass & -671.87 & 2 & 1347.80 & 67.90 & 0.00 \\
\hline mass_1 + mass_2 (20) & -637.86 & 3 & 1281.84 & 1.94 & 0.05 \\
\hline mass_1 + mass_2 $(21)$ & -637.48 & 3 & 1281.09 & 1.18 & 0.07 \\
\hline mass_1 + mass_2(22) & -637.34 & 3 & 1280.79 & 0.89 & 0.09 \\
\hline mass_1 + mass_2 (23) & -637.13 & 3 & 1280.39 & 0.48 & 0.11 \\
\hline mass_1 + mass_2(24) & -636.96 & 3 & 1280.04 & 0.13 & 0.13 \\
\hline mass_1 + mass_2 $(25)$ & -637.12 & 3 & 1280.35 & 0.44 & 0.11 \\
\hline mass_1 + mass_2(26) & -637.19 & 3 & 1280.51 & 0.60 & 0.10 \\
\hline mass_1 + mass_2 (27) & -636.89 & 3 & 1279.91 & 0.00 & 0.14 \\
\hline mass_1 + mass_2 (28) & -636.97 & 3 & 1280.07 & 0.16 & 0.12 \\
\hline mass_1 + mass_2(29) & -637.66 & 3 & 1281.44 & 1.54 & 0.06 \\
\hline mass_1 + mass_2 $(30)$ & -638.87 & 3 & 1283.85 & 3.95 & 0.02 \\
\hline mass_1 + mass_2 (31) & -640.56 & 3 & 1287.23 & 7.33 & 0.00 \\
\hline $\operatorname{mass} 1+\operatorname{mass} 2(32)$ & -642.16 & 3 & 1290.45 & 10.54 & 0.00 \\
\hline
\end{tabular}


Table S5: Best-fit SLR model for the association between wolf body mass (kg) and shoulder height $(\mathrm{cm})(N=204$ wolves $)$. Mass_1 is the slope before $27 \mathrm{~kg}$, and mass_2 is the slope after 27 $\mathrm{kg}$.

\begin{tabular}{lrrrrrr}
\hline Parameter & $\beta$ & SE & $Z$ & $P$ & {$[95 \%$ confidence interval $]$} \\
\hline constant & 22.42 & 4.34 & 5.16 & $<0.001$ & 13.86 & 30.99 \\
mass_1 & 1.97 & 0.17 & 11.60 & $<0.001$ & 1.63 & 2.30 \\
mass_2 & 0.23 & 0.05 & 4.65 & $<0.001$ & 0.13 & 0.33 \\
\hline
\end{tabular}


Figure S1: Observed shoulder height $(\mathrm{cm})$ versus body mass $(\mathrm{kg})$ for wolves $(N=204)$ with fitted linear spline curve from the best-fit SLR model (Table S5).

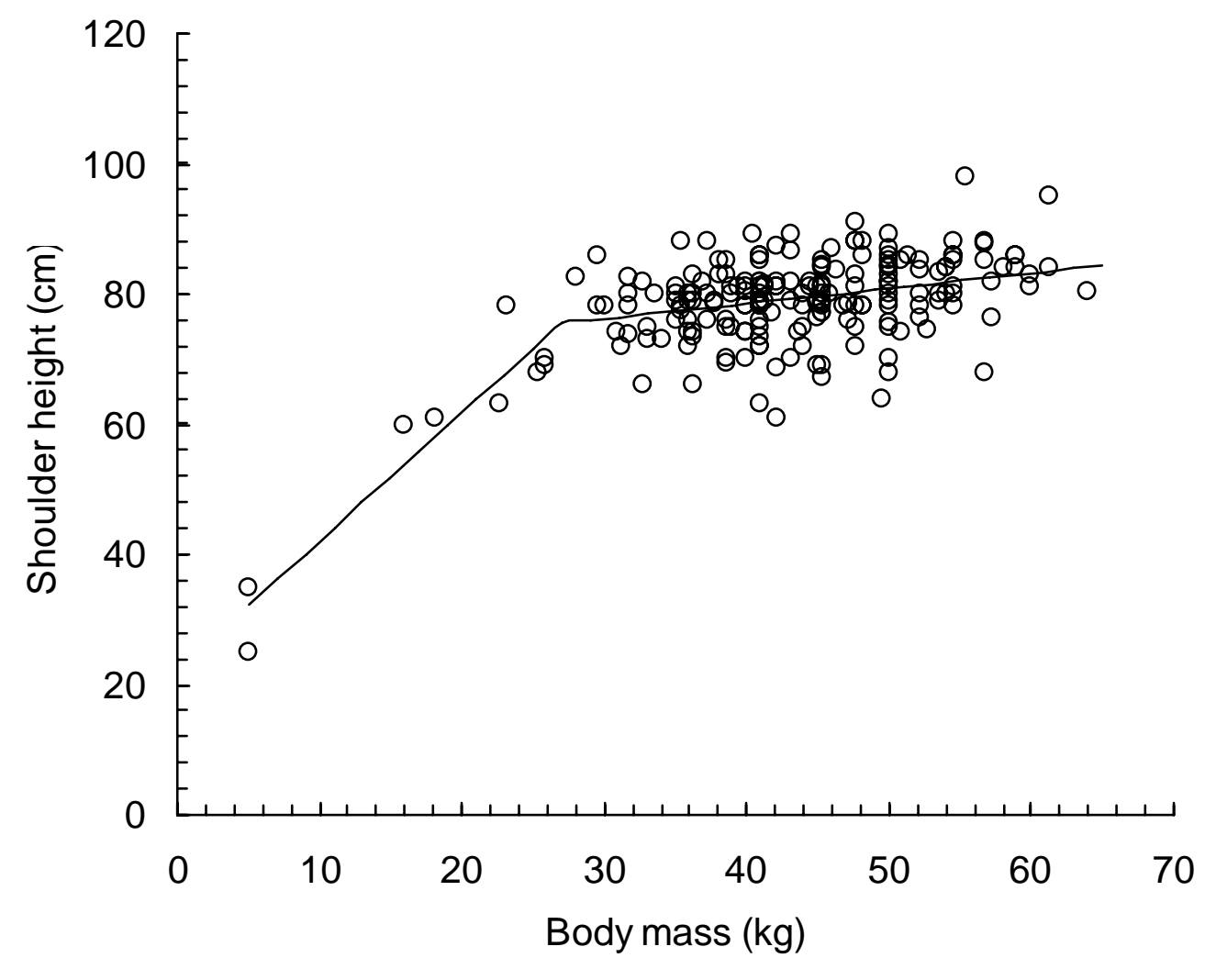

